IOSR Journal of Pharmacy

ISSN: 2250-3013, www.iosrphr.org

||| Volume 2 Issue 5 ||| Sep-Oct. 2012 ||| PP.38-43

\title{
Distributional record of five scleractinian corals from Andaman \& Nicobar Islands
}

\author{
Tamal Mondal*, C. Raghunathan \& K. Venkataraman ${ }^{1}$ \\ Zoological Survey of India, Andaman \& Nicobar Regional Centre, National Coral Reef Research \\ Institute, Haddo, Port Blair-744 102, Andaman \& Nicobar Islands, India \\ ${ }^{1}$ Zoological Survey of India, Prani Vigyan Bhawan, M- Block, New Alipore, Kolkata-700 053, India
}

\begin{abstract}
Andaman \& Nicobar Islands are the most promising areas with highly diversed faunal communities in its marine environment of Indo-Pacific basin. It showed a great variety of species richness in scleractinian corals. Five species of scleractinians such as Montipora turtlensis Veron \& Wallace, 1984; Montipora crassituberculata Bernard, 1897; Montipora effusa Dana, 1846 under Acroporidae family, Stylophora subseriata (Ehrenberg, 1834) belongs to Pocilloporidae family and Podabacia motuporensis Veron, 1990 belongs to Fungiidae family recorded from these Islands are new record to Indian waters. The present paper deals with the taxonomic features, ecology and distribution of those five newly recorded species.
\end{abstract}

Keywords-Sleractinian, Corals, New record, Andaman \& Nicobar Islands

\section{INTRODUCTION}

Species of coral reef communities are among the most fascinating of all biotic assemblages on earth. It is their rich diversity and strong biological interactions which characterizes the species of the community in an enriched manner (Karlson, 1999). Andaman \& Nicobar Islands is a chain of mountain separated in various groups by seas, channels and passages like Bay of Bengal, Andaman Sea, Alexandra Channel, Coco Channel, Cleugh Passage, Duncan Passage, Ten Degree Channel, Revello Channel, Sombero Channel, Saint George Channel and Great Channel, showed a healthy species composition, diversity and distribution (Tamal, 2011a \& 2012). These areas usually comprise of fringing reef in the continental shelf of most of the islands. The reefs are one of the major resources of islands economic stability through the controlled fishing practice and ever progressive eco-tourism. It has been estimated that 4-5\% of all described species on earth occur on tropical coral reefs (Reaka-Kudla, 1995). Approximately 91,000 species in these reefs are macroscopic from (73\%) representing a large number of taxa. This present paper describes taxonomic features of five species of scleractinian corals reported from Andaman \& Nicobar Islands are new record Indian waters.

\section{MATERIALS AND METHODS}

Extensive undersea surveys were conducted at various sites of North Andaman and Nancowry groups of islands in Andaman \& Nicobar Islands to study scleractinian corals by employing SCUBA (Self Contained Underwater Breathing Apparatus) diving during the period of March \& April 2012. Coral specimens were sampled and kept in fresh-water for few days to get only calcareous calcium carbonate structure and dried to examine detailed morphological characters for taxonomic study. Taxonomic identification was made following the keys of Veron and Pichon (1976), Veron and Pichon (1979), Veron and Wallace (1984) and Veron (2000) for identification. Corallites of the specimen were examined in detail to study the morphology for taxonomic analysis under stereo microscope (Leica, M 205 A). On completion of detailed structural study, the specimens were registered as paratype in National Zoological Collection of India and deposited at Zoological Survey of India, ANRC, Port Blair.

\section{RESULT}

Morphological analysis of five species of scleractinian corals were described below.

1. Montipora turtlensis Veron \& Wallace, 1984 Fig - 1

Family Acroporidae Verrill, 1902

Genus Montipora de Blainville, 1830 


\section{Material Examined}

Seven colonies were observed at Western Entrance region of Kamorta Island (Lat. 0759.517' N \& Long. $\left.93^{\circ} 30.373^{\prime} \mathrm{E}\right)$ during undersea survey on 19.04.2012 at the depth of 4 to $17 \mathrm{~m}$. A portion of colony was collected for detailed taxonomic study (Reg. No. : ZSI/ANRC- 7434).

Description

Colonies are flat, explanate plates which may develop nodular upwards growths towards their centre. Plates are bifacial with small, widely spaced corallites on the undersurface and a poorly developed epitheca. Nodular upwards growths may be widely separated or compacted to form sub-columnar expansions. Corallites are closely compacted, mostly immersed and have well defined thecae with calice. Septa are irregular with spines. Corallites on nodules have regular primary septa composed of tapered spines. Secondary septa are reduced to irregular rows of small spines. Corallites on nodules are surrounded by small fused papillae becoming sub-foveolate. The reticulum is coarse. Reticulum spinules and papillae spinules are usually of similar size and may become much elaborated.

\section{Habitat and ecology}

This species occurs in shallow, tropical reef environments. It is found in turbid environments and also in clear water habitats. This species is found to at least $20 \mathrm{~m}$.

\section{IUCN Red List Criteria and Category}

Vulnerable, 2012.

\section{Distribution}

India: Andaman \& Nicobar Islands; Elsewhere: Australia, Cambodia, Indonesia, Malaysia, Micronesia, Federated States of Myanmar, New Caledonia, Norfolk Island, Papua New Guinea, Philippines, Singapore, Solomon Islands, Taiwan, Province of China, Thailand, Vanuatu and Vietnam.

\section{Montipora crassituberculata Bernard, 1897 Fig -2}

Family Acroporidae Verrill, 1902

Genus Montipora de Blainville, 1830

\section{Material Examined}

Eleven colonies were observed at Western Entrance region of Kamorta Island (Lat. 07º59.517' $\mathrm{N} \&$ Long. $93^{\circ} 30.373^{\prime} \mathrm{E}$ ) during undersea survey on 19.04.2012 at the depth of 3 to $15 \mathrm{~m}$. A portion of colony was collected for detailed taxonomic study (Reg. No. : ZSI/ANRC- 7442).

\section{Description}

Colonies are sub-massive or are thick, sub-encrusting plates. Epithecae are well developed. Corallites are immersed to exsert and are conical in shape. Septa are very variable, even between the adjacent corallites. They are composed of non-tapered spines which may be regularly or irregularly arranged. Primary septa may be longer and fused. Directive septa are sometimes distinguishable. Secondary septa are sub-equal to absent and are usually slightly thinner than primaries. Thecae are usually well formed. Thecae and reticulum papillae are both compound and both are covered with elaborated spinules. The reticulum is coarse.

\section{Habitat and ecology}

This species occurs in shallow, tropical reef environments. It is found on upper and lower reef slopes.

\section{IUCN Red List Criteria and Category}

\section{Vulnerable, 2012.}

\section{Distribution:}

India: Andaman \& Nicobar Islands; Elsewhere: Australia, Cambodia, Chile, Fiji, Indonesia, Kiribati, Malaysia, Marshall Islands, Micronesia, Federated States of Myanmar, Nauru, New Caledonia, Palau, Papua New Guinea, Philippines, Pitcairn, Singapore, Solomon Islands, Sri Lanka, Taiwan, Province of China, Thailand, Tuvalu, Vanuatu, Viet Nam, Wallis and Futuna.

3. Montipora effusa Dana, 1846 Fig - 3

Family Acroporidae Verrill, 1902

Genus Montipora de Blainville, 1830

\section{Material Examined}

Six colonies were observed at Western Entrance region of Kamorta Island (Lat. 0759.517'N \& Long. $93^{\circ} 30.373^{\prime}$ E) during undersea survey on 19.04.2012 at the depth of 3 to $12 \mathrm{~m}$. A portion of colony was collected for detailed taxonomic study (Reg. No. : ZSI/ANRC-7438). 


\section{Description}

Colonies are submassive or form extensive thick uni-facial plates. Corallites are small and exsert with elongate thecal papillae. The colony surface is rough in appearance.

Habitat and ecology

This species occurs in most shallow, tropical reef environments.

IUCN Red List Criteria and Category

Near Threatened, 2012.

Distribution

India: Andaman \& Nicobar Islands; Elsewhere: American Samoa, Australia, British Indian Ocean Territory, Comoros, Cook Islands, Fiji, French Polynesia, Indonesia, Japan, Kenya, Kiribati, Madagascar, Malaysia, Mauritius, Mayotte, Mozambique, Nauru, New Caledonia, Niue, Papua New Guinea, Philippines, Réunion, Samoa, Seychelles, Singapore, Solomon Islands, Somalia, Sri Lanka, Taiwan, Province of China, Tanzania, United Republic of Thailand, Tokelau, Tonga, Tuvalu, Vanuatu, Wallis and Futuna.

4. Stylophora subseriata (Ehrenberg, 1834) Fig - 4

Family Pocilloporidae Lamarck, 1816

Genus Stylophora Schweigger, 1819

\section{Material Examined}

34 colonies were observed at Western Entrance region of Kamorta Island (Lat. 0759.517'N \& Long. $93^{\circ} 30.373^{\prime} \mathrm{E}$ ) during undersea survey on 19.04.2012 at the depth of 4 to $18 \mathrm{~m}$. A portion of colony was collected for detailed taxonomic study (Reg. No. : ZSI/ANRC-7441).

Description

Colonies are usually irregular, anastomosing branches with blunt end. Corallites are without prominent hoods, but the corallites are prominent. The Columellae are style like with 6 primary septa. These are may be short or fused with columella. Spines are present as the cover of coenosteum . Calice structures are variable in colony.

\section{Habitat and ecology}

It is found in most reef environments. The maximum size is approximately $25 \mathrm{~cm}$ across. This species is found to $30 \mathrm{~m}$.

\section{IUCN Red List Category and Criteria}

Least Concern, 2012.

\section{Distribution}

India: Andaman \& Nicobar Islands; Elsewhere: Australia, Bahrain, British Indian Ocean Territory, Comoros, Djibouti, Egypt, Eritrea, Fiji, Indonesia, Iran, Islamic Republic of Iraq, Israel, Jordan, Kenya, Kiribati, Kuwait, Madagascar, Malaysia, Marshall Islands, Mauritius, Mayotte, Micronesia, Federated States of Mozambique, Nauru, New Caledonia, Oman, Pakistan, Palau, Papua New Guinea, Philippines, Qatar, Réunion, Saudi Arabia, Seychelles, Singapore, Solomon Islands, Somalia, South Africa, Sudan, Tanzania, United Republic of Thailand, Tuvalu, United Arab Emirates, United States Minor Outlying Islands, Vanuatu and Yemen.

\section{Podabacia motuporensis Veron, 1990 Fig -5}

Family Fungiidae Dana, 1846

Genus Podabacia Milne Edwards and Haime, 1849

\section{Material Examined}

5 colonies were observed at off Shibpur, Diglipur (Lat. $13^{\circ} 14.439^{\prime} \mathrm{N}$ \& Long. $92^{\circ} 02.971$ 'E) during undersea survey on 03.03.2012 at the depth of 5 to $14 \mathrm{~m}$. A portion of colony was collected for detailed taxonomic study (Reg. No. : ZSI/ANRC-7292).

Description

Colonies are attached, encrusting, unifacial. A central corallite is sometimes visible. Peripheral corallites are small. These are not strongly inclined towards the margin of plate. Septa are bending towards the secondary centres from where they will radiate. Primary and secondary septa are alternate. Both the septa are strongly dentate but the height of primary septa is greater than the secondary one. Columellae are very tiny or absent.

\section{Habitat and ecology}

This species is found in reef slope as an attached polyp with multiple mouths. Maximum size is over 50 $\mathrm{cm}$. This species is found from $5-20 \mathrm{~m}$. 


\section{IUCN Red List Category and Criteria:}

Near Threatened, 2012.

\section{Distribution}

India: Andaman \& Nicobar Islands; Elsewhere: Australia, British Indian Ocean Territory, Comoros, Fiji, Indonesia, Kenya, Kiribati, Madagascar, Malaysia, Marshall Islands, Mauritius, Mayotte, Micronesia, Federated States of, Mozambique, Nauru, New Caledonia, Palau, Papua New Guinea, Philippines, Réunion, Seychelles, Singapore, Solomon Islands, Somalia, Taiwan, Province of China, Tanzania, United Republic of Tuvalu, Vanuatu, Vietnam.

\section{DISCUSSION}

Taxonomical study on scleractinian corals in the context of Indian marine biological research was made by Pillai in 1971 for the first time. Basic taxonomical study of scleractinians is a firsthand tool to identify species with the similarities and dissimilarities of morphological characters of individuals. Different characters of calcareous skeleton structures are considered as the parameter for the indentifying species name. It is the study of calcareous structure with their orientation pattern along with the present environmental condition. As ecology is one of the major stressors to build the structural confirmation of scleractinian life, ecological study was also started in past decades. Sewell (1922) provided the first account of the ecology and formation of reef in the region after visiting the Nicobar Islands. Pillai (1983) listed 135 coral species from the region and found that the Andaman Islands were less diverse than the Nicobar Islands. Venkataraman et al. (2003) described as well as listed 228 species of corals of Andaman \& Nicobar Islands, Lakshadweep, Gulf of Kutch, Gulf of Mannar and Palk Bay belonging to 58 genera and 15 families. Ramakrishna et al. (2010) reported checklist of a total of 418 scleractinian coral species from the Andaman \& Nicobar Archipelago. Tamal et al.(2010a-c \& 2011b-h) with the extensive surveys in underwater marine life, reported 73 species of scleractinian corals from different areas of these entire group of islands as new record to Indian water. Tamal et al. (2011a, i \& 2012) also listed 244 species from North \& Middle Andaman Islands, 34 species of corals from Little Andaman Islands and 168 species of corals from Ritchie's Archipelago. New record of five scleractinian corals will increase the species content of those study areas of Andaman \& Nicobar Islands over and above in India. Taxonomic description of this paper is addition of five scleractinian species along with the existing database of corals previously known form Indian waters.

\section{ACKNOWLEDGEMENT}

Authors are grateful to the Ministry of Environment and Forests, Government of India for providing financial assistance to undertake the study through the projects of National Coral Reef Research Institute, Zoological Survey of India, Port Blair.

\section{REFERENCES}

[1]. Blainville, H.M. de (1830) Zoophytes. In 'Dictionnaire des Science naturellus', Paris. 60:295-363.

[2]. Dana, J.D. (1846) Zoophytes. U.S. Exploring Exped 1838-1842.

[3]. Karlson, R.H. (1999) Dynamics of Coral Communities. Kluwer Academic Publishers, Netherlands.

[4]. Lamarck, J.B.P. De (1816) Histories naturelle des Animaux sans vertebres. Paris. 2:1-568.

[5]. Milne Edwards, H. \& Haime, J. (1849) Researches sur les polipiers Monographie des Astreides. Suit 1 Astreens agglomeres. Ann. Sci. Nat. (Zool.), 11:233-312.

[6]. Pillai, C.G.S. (1971) Stony corals of the seas around India. Proc. Symp. Corals and coral reefs, Mandapam Camp, Jan. 1969. 191-216.

[7]. Pillai, C.G.S. (1983) Structure and genetic diversity of recent scleractinian of India. J. Mar. Bio. Assoc. India, 25: 78-90.

[8]. Ramakrishna, Tamal Mondal, Raghunathan, C., Raghuraman, R. \& Sivaperuman, C. (2010) New Records of Scleractinian Corals in Andaman \& Nicobar Islands. Rec. zool. Surv. India, Occ. Paper No, 321: 1-144.

[9]. Reaka-Kudla, M.L. (1995) An estimate of known and unknown biodiversity and potential for extinction on coral reefs. Reef Encounter, 17:8-12.

[10]. Schweigger,A.F. (1819) Beobachtungen auf naturhistorischen Reisen-Anat. Physiol. Untersuchungen ueber Corallen. Berlin.

[11]. Sewell, R.B.S. (1922) A survey season in the Nicobar Islands on the R.I.M.S. Ínvestigator” October 1921 to March 1922. Journal of the Bombay Natural History Society, 28: 970-989.

[12]. Tamal Mondal, Raghunathan, C. \& Ramakrishna. (2010a) New record of thirteen Scleractinian Corals in Indian waters from Middle and North Andaman. Biosystematica, 4: 75-89.

[13]. Tamal Mondal, Raghunathan, C. \& Ramakrishna. (2010b) New record of nine Scleractinian Corals from Rutland Island, Andaman. Int. J. Biol. Sci., 1:155-170.

[14]. Tamal Mondal, Raghunathan, C., Sivaperuman, C. \& Ramakrishna (2010c) Identification of seven Scleractinian Corals from Andaman \& Nicobar Island as New Record to Indian Water. Proc. Zool. Soc, 63: 61-66.

[15]. Tamal Mondal, Raghunathan, C. \& Venkataraman, K. (2011a) Diversity of Scleractinian Corals in Middle and North Andaman Archipelago. World Journal of Zoology, 6(4):407-419 
[16]. Tamal Mondal, Raghunathan, C. \& Ramakrishna. (2011b) New record of five Scleractinian Corals from Rutland Island, South Andaman Archipelago. Asian J. Exp. Biol Sci., 2: 114-118.

[17]. Tamal Mondal, Raghunathan, C. \& Ramakrishna. (2011c) Notes on three new records of scleractinian corals from Andaman Islands. Journal of Oceanography and Marine Science, 2:122-126.

[18]. Tamal Mondal, Raghunathan, C. \& Ramakrishna. (2011d) Occurrence of seven Scleractinian Corals in Ritchie's Archipelago, Andaman Islands of India. Proc. Zool. Soc., 64:57-61.

[19]. Tamal Mondal, Raghunathan, C. \& Ramakrishna. (2011e) New Record of Six Scleractinian Corals to Indian Water from Rani Jhansi Marine National Park, Andaman \& Nicobar Archipelago. International Journal of Science and Nature, 2:321-326.

[20]. Tamal Mondal, Raghunathan, C. \& Ramakrishna. (2011f) Addition of thirteen Scleractinians as New Record to Indian Water from Rutland Island, Andamans. Asian J. Exp. Biol. Sci., 2(3): 383-390.

[21]. Tamal Mondal, \& Raghunathan, C. (2011g) New record of two Scleractinian Corals from Neil Island, Ritchie's Archipelago. International Journal of Plant, Animal and Environmental Sciences, 1:76-79.

[22]. Tamal Mondal, Raghunathan, C. \& Venkataraman, K. (2011h) Five Scleractinian Corals as a new record from Andaman Islands- A New Addition to Indian Marine Fauna. World Journal of Fish and Marine Sciences, 3: 450458.

[23]. Tamal Mondal, Raghunathan, C. \& Ramakrishna (2011i) New recruitment of scleractinian corals in little Andaman Island after tsunami. Indian Journal of Geo-Marine Science, 40(5):653-656.

[24]. Tamal Mondal, Raghunathan C. \& Venkataraman, K. (2012) Scleractinian Diversity of Ritchie's Archipelago, Andaman \& Nicobar Island. GJSFR, 12(4):53-64.

[25]. Venkataraman, K., Satyanarayan, C., Alfred, J.R.B. \& Wolstenholme, J. (2003) Handbook on Hard Corals of India., 1-266.

[26]. Verrill, A.E. (1902) Notes on corals of the genus Acropora (Madrepora Lam.) with new description and figures of types, and of several new species. Trans. Connecticut Acad. Arts,. Sci., 11:207-266.

[27]. Veron, J.E.N. \& Pichon, M. (1976) Scleractinian of Eastern Australia. Part I. Australian Institute of Marine Science.

[28]. Veron, J.E.N. \& Pichon, M. (1979) Scleractinia of Eastern Australia. Part III. Australian Institute of Marine Science.

[29]. Veron, J.E.N. \& Wallace, C.C. (1984) Scleractinia of Eastern Australia. Part V.Family Acroporidae. Australian Institute of Marine Science. p 1-485.

[30]. Veron, J.E.N. (2000) Corals of the World. Australian Institute of Marine Science,1-3 volumes.
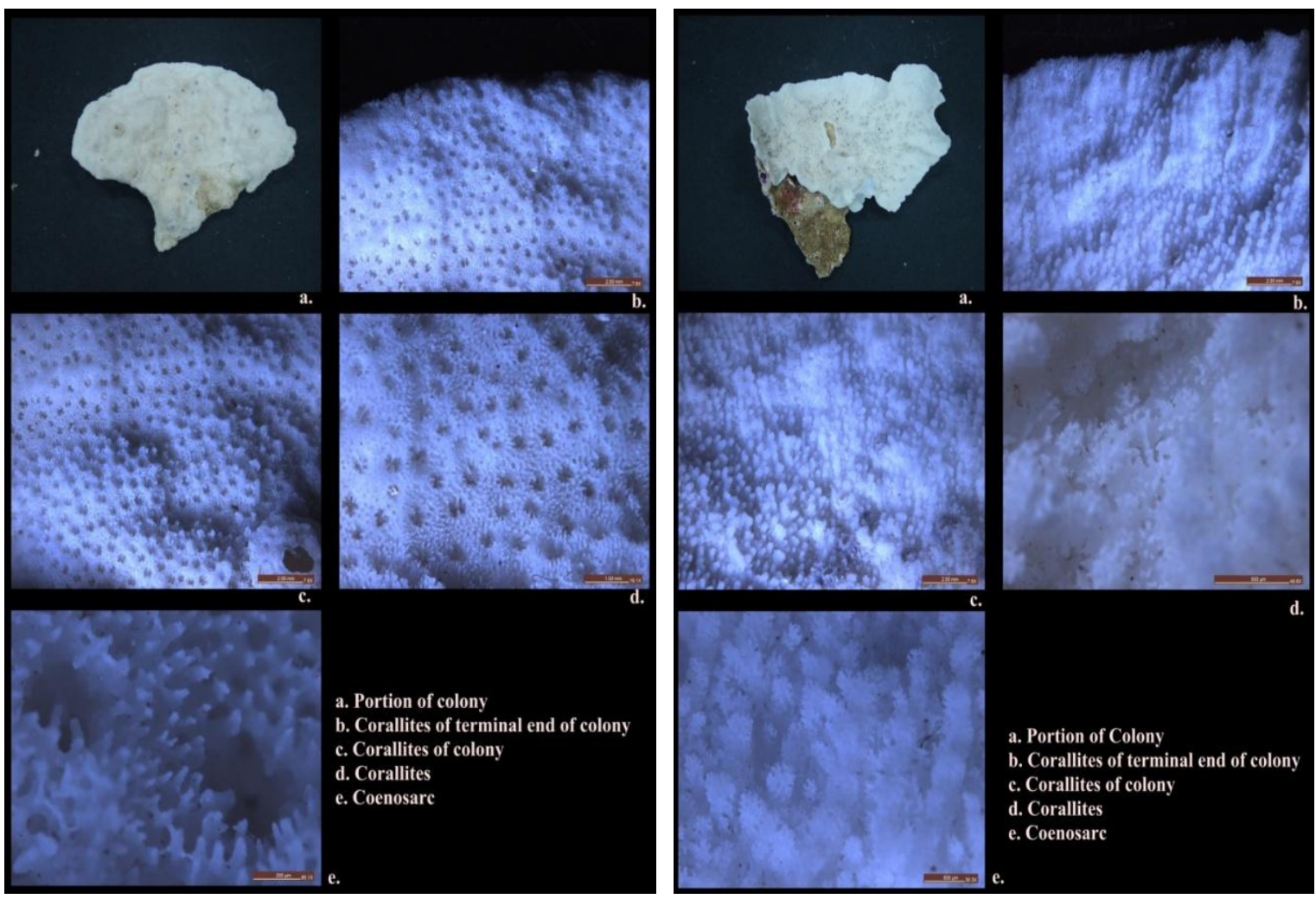

Fig 1 Montipora turtlensis Veron \& Wallace, 1984

Fig 2 Montipora crassituberculata Bernard, 1897 

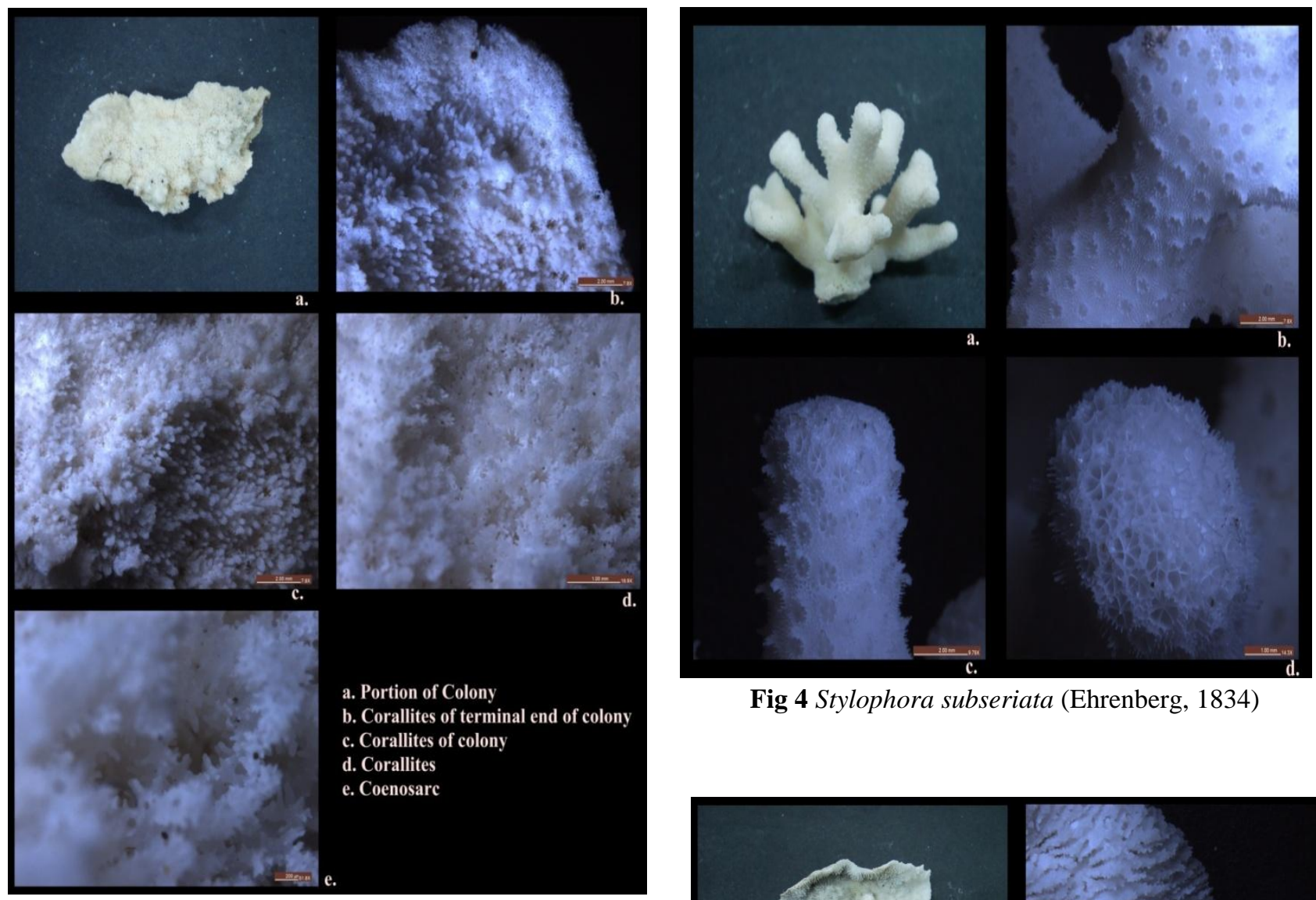

Fig 4 Stylophora subseriata (Ehrenberg, 1834)

Fig 3 Montipora effusa Dana, 1846

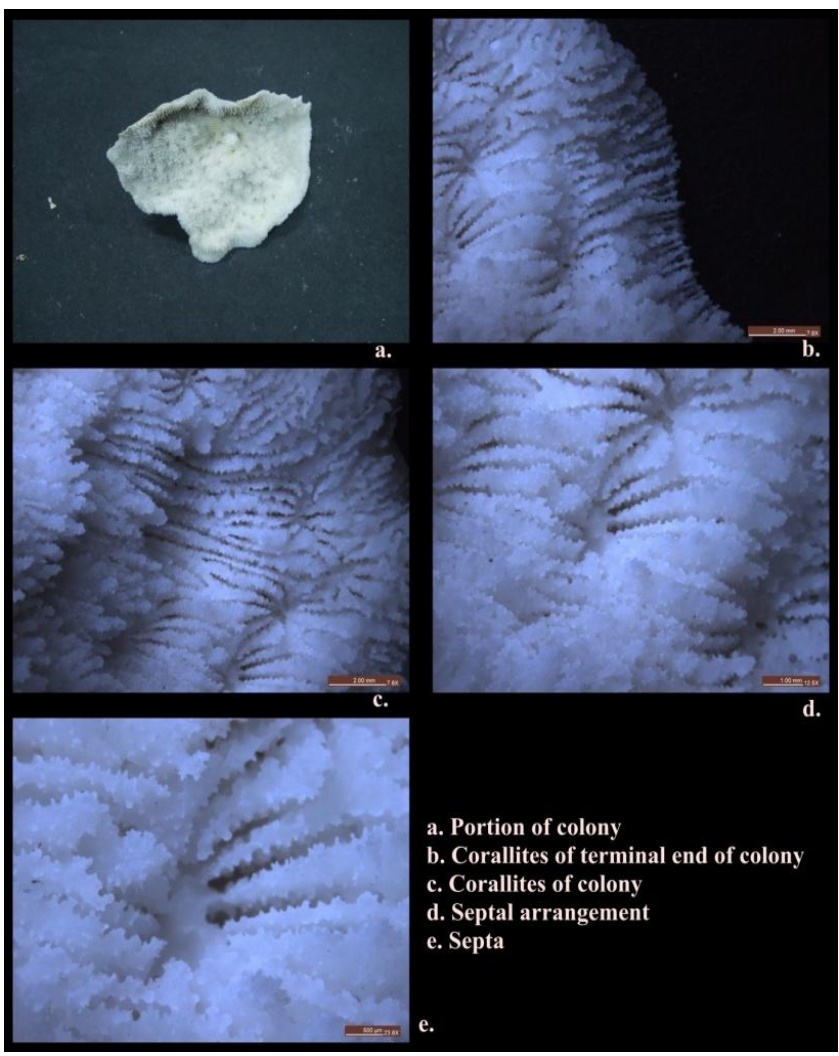

Fig 5 Podabacia motuporensis Veron, 1990 